\title{
Allelopathy of Sage and White Wormwood on Purslane Germination and Seedling Growth
}

\author{
Alireza PIRZAD ${ }^{1)}$, Vahid GHASEMIAN ${ }^{2}$, Reza DARVISHZADEH ${ }^{12}$, \\ Mohammad SEDGHI ${ }^{3}$, Abbas HASSANI ${ }^{4}$, Andrea ONOFR ${ }^{5}$ ) \\ 1) Urmia University, Faculty of Agriculture, Department of Agronomy and Plant Breeding, \\ Urmia,Iran;a.pirzad@urmia.ac.ir,r.darvishzadeh@urmia.ac.ir \\ ${ }^{2)}$ Tarbiat Modarres University, Faculty of Agriculture, Iran; ghasemianvahid@yahoo.com \\ ${ }^{3)}$ University of Mohaghegh Ardabili, Faculty of Agriculture, Department of Agronomy and Plant Breeding, Ardabil, Iran; mosedghi2003@yahoo.com \\ 4) Urmia University, Institute of Biotechnology, Department of Medicinal and Industrial Plants, Urmia, Iran; horthasani@yahoo.com \\ ${ }^{5)}$ University of Perugia, Department of Agricultural and Environmental Sciences, Perugia, Italy; onofri@unipg.it
}

\begin{abstract}
A bioassay run was carried out in the incubator to evaluate possible allelopathic effects of water extracts of sage and white wormwood on germination and seedling growth of purslane. Results showed that the type of extract and its concentration $(0,5,10,15$ and 20\%) significantly influenced final germination percentage, germination rate and index, root and shoot length, root/shoot ratio, fresh and dry weight of seedling of purslane. The interaction between these two experimental factors was always significant, producing different results according to the different combination levels. The statistical comparison of means indicated that the maximum germination percentage and germination rate (respectively $68 \%$ and $11.4 \% \mathrm{~d}^{-1}$ ) were obtained from the untreated control ( $0 \%$ extract), while the lowest values for the same two characters occurred with $15 \%$ of sage (respectively $45 \%$ and $\left.6.4 \% \mathrm{~d}^{-1}\right)$ and $20 \%$ of white wormwood $\left(38 \%\right.$ and $\left.7.5 \% \mathrm{~d}^{-1}\right)$. Concerning germination indexes, the highest (55) and the lowest (32) values were observed respectively on the control and with $15 \%$ of sage extract or $20 \%$ of white wormwood extract. The longest $(4.5 \mathrm{~cm})$ and the shortest $(1.3 \mathrm{~cm})$ root of purslane were obtained with $5 \%$ of white wormwood and $20 \%$ of sage extracts, respectively. Changes in shoot length with sage and white wormwood extracts were similar to those in root length, even though shoot length was less affected by the concentration of extracts. Root and shoot length changes brought to maximum (22.0) and minimum (8.9) values for the root/shoot length ratio, respectively with 5\% of white wormwood and $20 \%$ of sage extracts. The maximum fresh $(2.111 \mathrm{~g})$ and dry $(0.338 \mathrm{~g})$ seedling weight of purslane were obtained from untreated control, producing the same seedling weight with $5 \%$ of sage, 5 and $10 \%$ of white wormwood extract. While the minimum fresh $(0.692 \mathrm{~g})$ and dry $(0.111 \mathrm{~g})$ seedling weight were obtained from $15 \%$ of white wormwood extract, so that there is no significant differences between this value and the seedling weight produced under 10,15 and $20 \%$ of sage and $20 \%$ of white wormwood extract.
\end{abstract}

Keywords: Arthemisia sieberi, germination, Portulaca oleracea, purslane, sage, Salvia officinalis, seedling

\section{Introduction}

Allelopathy interactions are primarily based on the ability of certain plant species to produce secondary chemical compounds, that exert some sort of biological effects on other organisms, many of which are still unknown (Waller, 2004). Allelopathic compounds are released into the environment through root exudation, leaching by dews and rains and volatilization from decaying plant tissues (Rice, 1984). In most cases, these compounds inhibit the germination or growth of neighboring plants, although sometimes they may show a stimulating effect (Ebana $e t$ al., 1981). Inhibitory effects of allelophatic plants may be exploited within an integrated weed management system to modify crop-weed interactions and lower the need for chemical means of weed control; indeed, yield losses caused by weeds are well documented in many studies and it has been shown that these losses may frequently be high- er than those caused by pests and diseases (Culter, 1988; Steinsiek et al., 1982).

This present study considered a very widespread species, i.e. Portulaca oleracea L. (purslane). Although it is characterized by several ecological types, some of which are occasionally used as vegetables in human dietary (Miyanishi and Cavers, 1980), this plant species is mainly regarded as a drought hardy weed, colonizing waste places and bare areas, but also thriving in moist and fertile soils. Overall, purslane is considered as a serious threat to cultivated fields, throughout tropical, subtropical and temperate areas, attaining this status more because of its very widespread importance, than by being amongst the top few weeds in any one country. Indeed, purslane was ranked $9^{\text {th }}$ of the world's worst weeds, being recorded in 45 crops in 81 countries (Holm et al., 1977), it showed a rating of 10 in Southeast Asia, while it was ranked 6th in the Pacific and 49th in Australia (Waterhouse, 1993a, 
92

b). In Southeast Asia, it is particularly important in many upland crops, including vegetables, rice, maize, sorghum, groundnuts and sugarcane.

Purslane, as an important weed (Duke, 1987), is a fleshy annual herb, reproducing by seeds, or by stem-fragments rooting when lying on moist soil. The stems are succulent, often reddish and 0.2 to $0.5 \mathrm{~m}$ in length. The leaves are alternate and frequently clustered at the end of branches; flowers are yellow, sessile, self-pollinated and occur either singly or several together in the above mentioned leaf clusters. Flowers open on sunny mornings and produce numerous (up to 243000 per plant), tiny ( $0.5 \mathrm{~mm}$ diameter) and black seeds (Waterhouse, 1994). These latter are spread by wind, water, as contaminants of crop seeds and by birds, surviving passage through the digestive tract. They also survive burial for long periods and germinate best above $30^{\circ} \mathrm{C}$, but poorly below $24^{\circ} \mathrm{C}$ (Waterhouse, 1994).

Though it does not compete well with other weeds, it is often successful because it establishes rapidly after soil disturbance and may flower and set its seeds before being out competed by taller plants. The succulent leaves and stems are rich in oxalates and nitrates and have been implicated in livestock deaths (Miyanishi and Cavers, 1980).

Two plant genera with potential allelopathic effects were considered in this study, i.e. Salvia and Artemisia. Concerning the first one, fifty-eight species of Salvia (sage; family of Lamiaceae) are found in Iran, seventeen of which are endemic (Mozaffarian, 1996). Several of these species have been reported to produce secondary metabolites with medicinal usage (Hitokoto et al., 1980). Among these, Salvia officinalis L. is very widespread; it is a semiwoody shrub reaching a height of $60 \mathrm{~cm}$ and originates from the Mediterranean regions of North Africa, Spain and the Balkans. It has been grown as a medicinal and culinary herb for thousands of years and it can now be found everywhere in gardens (D’Antunono et al., 2002). A comparison of the composition of the Iranian sage oils during the different developmental stages revealed that 1,8 cineole (15.3-22\%), $\alpha$-thujone (9.1-25.1\%) and $\beta$-pinene (7.1-16.4\%) were the principal components (Mirjalili et al., 2006).

Artemisia (family of Asteraceae) is the largest and most widely distributed genus among the approximately 60 belonging to the tribe of Anthemideae. This genus comprises a variable number of species, ranging from 200 to over 400 , which are predominantly distributed in the northern regions of the world, within the $0-50 \mathrm{~cm}$ precipitation area (Tan et al., 1998). Thirty-four species of Artemisia are reported in Iran and some of them are endemic. In Iranian folk medicine, some species of Artemisia are used for their various medicinal properties and local people used aerial parts of these plants for their antiviral and spasmolytic effects (Ramezani et al., 2004).

Within this genus, Artemisia sieberi Bess. (white wormwood) is widely distributed in desert areas of Iran (Mozafarian, 1988). The main components of essential oil of Artemisia sieberi from Iran were found to be camphor (44-49.3\%), 1,8-cineole (11.1-19\%), bornyl acetate (5.8\%) and camphene (5\%) (Weyerstahl et al., 1993). In other studies, thirty-one compounds were identified, including $\beta$-thujone (19.8\%), camphor (19.5\%), $\alpha$-thujone (10.6\%), verbenole (9.7\%), $\rho$-mentha-1,5-dien-8-ol (6.4\%) and 1,8-cineole (5.7\%) (Ghorbani-Ghouzhdi et al., 2008). Considering A. sieberi from the Kerman province of Iran, the main components of essential oil were (a) in non-grazed sites were: 1,8-cineol (29.9\%), myrcene (14.1\%); (b) in moderate grazed site: myrcene (15.9\%), 1,8 cineol (15.1\%), Eudesm-7(11)-en-4-ol (11.1\%); (c) in heavy grazed site: 4-tepinyl acetate (23.3\%), davanone (21.9\%),p-cymene (19\%) (Bagheri et al., 2007).

Recently, the interest in the application of essential oils to control plants and post harvest pathogens has increased and their potential role in food preservation has been exploited (Lanciotti et al., 2004; Vazquez et al., 2001). However, $S$. officinalis and $A$. sieberi can also play an allelopathic role, because their components might exert an inhibitory effect on seed germination and seedling growth of $P$. oleracea, even though no data is available in literature with this respect.

The aim of this study was to evaluate the allelopathic potential of water extracts obtained from $S$. officinalis and A. sieberi, with respect to the above mentioned weed species (P. oleracea).

\section{Materials and methods}

Aerial parts of $S$. officinalis $\mathrm{L}$. and A. sieberi were collected from the Urmia region (Iran), were air dried at room temperature $\left(20-25^{\circ} \mathrm{C}\right)$ and were ground by an electric grinder. Water extracts were prepared at concentrations of $0,5,10,15$ and $20 \%$. To prepare 20,15, 10, and $5 \%$ of extract $40,30,20$, and $10 \mathrm{~g}$ dry matter of both species soaked in $30^{\circ} \mathrm{C}$ distilled water during 48 hours, so that it produced $200 \mathrm{ml}$ extract, respectively.

Seeds of Portulaca oleracea were collected at the Research Farm of the University of Urmia (1320 m above sea level, $37^{\circ} 32^{\prime} \mathrm{N}, 45^{\circ} 5^{\prime} \mathrm{E}$ ), Iran. They were sterilised with sodium hypochloride (10\%) and washed by distilled water. For each treatment, one hundred seeds were randomly placed in four Petri dishes with $9 \mathrm{~cm}$ diameter, lined with two Whatman discs with filter paper No. 1 at the bottom. Three $\mathrm{ml}$ of deionized water were added to each dish at the beginning of the experiment, by using a pipette. Considering water extract type ( $S$. officinalis and $A$. sieberi) and concentration $(0,5,10,15$ and $20 \%)$, the experiment was organised according to a two - factor factorial, randomised complete block design with four replicates.

Germination assays were conducted in an incubator at constant temperature of $25^{\circ} \mathrm{C}$ in darkness, for six days. Germinated seeds from individual Petri dishes were counted and removed every day at an interval of 24 hours. A seed was considered as germinated when radicle protru- 
sion was more than $2 \mathrm{~mm}$ length. The final germination percentage, average germination rate (n. per day) and germination index were measured for each Petri dish as follows (Ellis and Roberts, 1981; Maguire, 1962):

\section{Germination Rate $=\Sigma X n / Y n$}

Germination Index $=\Sigma(\mathrm{Xn} / \mathrm{Yn})$ days.

in which, $\mathrm{Xn}$ was percentage of germinated seeds at $\mathrm{Yn}$

Fifteen germinated seedlings of $P$. oleracea from each Petri dish were grown in light during day and darkness during night under treatment conditions (different concentrations of extracts) until cotyledonal leaves fully opened and then root length, shoot length, seedling fresh and dry weight were measured.

Statistical analysis: All data were submitted to ANOVA. A graphical inspection of residuals showed that the basic assumptions for linear models were not severely violated and that stabilizing transformations were not needed for any of the measured variables. As regression models could not be successfully fitted into this dataset, means were separated by using a protected Least Significant Difference (LSD), at $\mathrm{p}=0.05$. All the analyses were performed by using the statistical package MSTATC software.

\section{Results and discussion}

Results of analyses showed that the effects of extract type (sage and white wormwood), concentration of extract $(0,5,10,15$ and $20 \%)$ and their interaction on final percentage germination, germination rate and index, root and shoot length, root/shoot length ratio, seedling fresh and dry weight were significant (Tab. 1).

Mean comparisons indicated that the maximum germination percent $(68 \%)$ was obtained on the control $(0 \% \mathrm{ex}$ tract) treatment. Application of $5 \%$ sage and white wormwood extracts produced final germination percentages of 56 and $61 \%$, respectively. At higher concentrations, final germination percentages decreased progressively, down to minimum values of 45 and $38 \%$, respectively at $15 \%$ sage and $20 \%$ of white wormwood (Fig. 1-I).

The germination rate of $P$. oleracea under different concentrations of both sage and white wormwood extracts showed the same trend as final germination percentage (Fig. 1-II), i.e. the maximum and minimum germination rates were obtained respectively on the control treatment $\left(11.4 \% \mathrm{~d}^{-1}\right)$ and with either $15 \%$ of sage $\left(6.4 \% \mathrm{~d}^{-1}\right)$ or $20 \%$ of white wormwood $\left(7.5 \% \mathrm{~d}^{-1}\right)$ extracts.

Considering the germination index, the highest value was observed in the control treatment (55.1) that was not significantly different from that observed with extracts at concentrations of 5 and $10 \%$ of sage and 5, 10 and $15 \%$ of white wormwood. On the other hand, the lowest germination index (31.7) was obtained with $15 \%$ of sage that was not significantly different from that obtained with $20 \%$ of sage and white wormwood (Fig. 1-III).
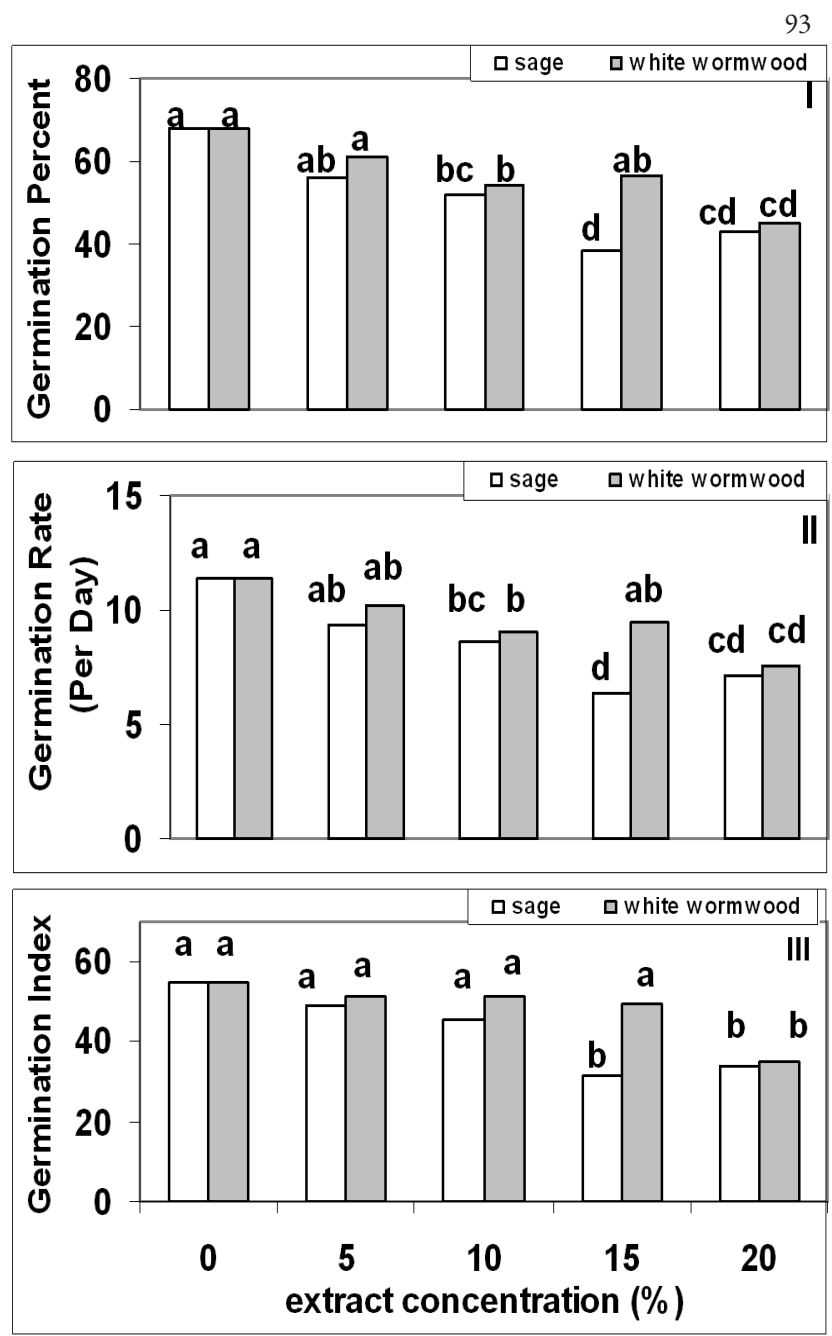

Fig. 1. Means comparisons of interaction effects between extract origin (sage and white wormwood) and concentration on germination percent (I), rate (II) and index (III) of Portulaca oleracea seeds. The same letters show non significant differences

The highest root length of $P$. oleracea $(4.5 \mathrm{~cm})$ was obtained from extracts at $5 \%$ concentration of white wormwood that was significantly higher than the value obtained from control treatment. Increasing the concentration of white wormwood led to shorter purslane roots and such an effect was on average higher with sage extracts., so that the shortest root $(1.3 \mathrm{~cm})$ was obtained with $20 \%$ of sage extract (Fig. 2-I).

Changes in shoot length were on average smaller than those in root length, and significant differences were only observed between plants treated with $5 \%$ white wormwood or sage and plants treated with $10 \%$ sage (Fig. 2-II).

Trends in root and shoot lengths led to maximum (22.0) and minimum (8.9) root/shoot length ratios with $5 \%$ of white wormwood and $20 \%$ of sage, respectively. Variations in root/shoot length ratio followed closely variations in root length, thus this latter variable appeared to affect the above ratio more than shoot length (Fig. 2-III).

The maximum fresh $(2.1 \mathrm{~g})$ and dry $(0.39 \mathrm{~g})$ weight of purslane seedlings were obtained from the control treat- 
94

Tab. 1. Analysis of variance (MS) of sage and white wormwood water extracts effect on germination and seedling growth of purslane

\begin{tabular}{|c|c|c|c|c|c|c|c|c|c|}
\hline \multirow{2}{*}{$\begin{array}{l}\text { Source of } \\
\text { Variation }\end{array}$} & \multirow{2}{*}{$\mathrm{df}$} & \multicolumn{3}{|c|}{ Germination } & \multicolumn{3}{|c|}{ Length } & \multicolumn{2}{|c|}{ Seedling } \\
\hline & & Percent & Rate & Index & Root & Shoot & Root/Shoot & Fresh weight & Dry weight \\
\hline Replication & 3 & $0.004^{\mathrm{ns}}$ & $0.004^{\mathrm{ns}}$ & $0.001^{\mathrm{ns}}$ & $0.500^{*}$ & $0.0003^{\mathrm{ns}}$ & $0.009^{\mathrm{ns}}$ & $0.001^{\mathrm{ns}}$ & $0.001^{\mathrm{ns}}$ \\
\hline Extract (A) & 1 & $0.025^{\circ \prime}$ & $0.025^{*}$ & $0.030^{*}$ & $3.469^{\prime \prime}$ & $0.002^{\mathrm{ns}}$ & $0.029^{\circ}$ & $0.014^{\circ}$ & $0.010^{*}$ \\
\hline Concentration (B) & 4 & $0.047^{*}$ & $0.047^{*}$ & $0.056^{*}$ & $5.493^{*}$ & $0.002^{\mathrm{ns}}$ & $0.104^{\prime \prime}$ & $0.088^{*}$ & 0.066 \\
\hline $\mathrm{A} \times \mathrm{B}$ & 4 & $0.009^{*}$ & $0.009^{*}$ & $0.013^{*}$ & $1.633^{*}$ & $0.004^{" \prime}$ & $0.024^{\circ}$ & $0.029^{*}$ & $0.021^{*}$ \\
\hline Error & 27 & 0.002 & 0.002 & 0.002 & 0.095 & 0.001 & 0.006 & 0.002 & 0.001 \\
\hline C.V. $(\%)$ & & 2.53 & 4.61 & 2.41 & 11.01 & 17.45 & 6.53 & 12.29 & 16.58 \\
\hline
\end{tabular}

ns, ${ }^{*},{ }^{* *}$ : non- significant and significant at $\mathrm{P}<0.05$ and $\mathrm{P}<0.01$, respectively; df: Degrees of Freedom
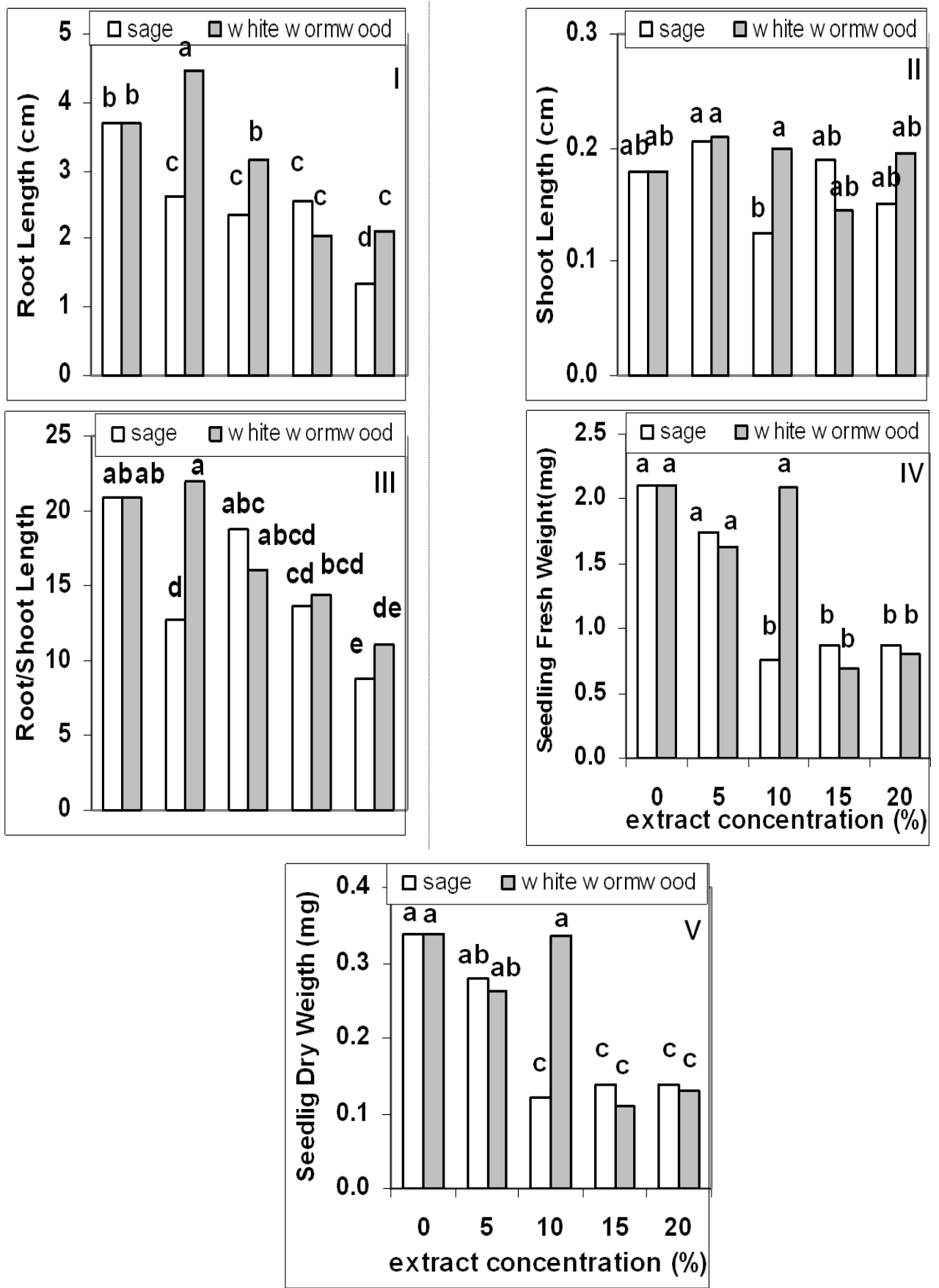

Fig. 2. Means comparisons of interaction effects between extract origin (sage and white wormwood) and concentration on root length (I), shoot length (II), root/shoot length (III), seedling fresh weight (VI) and seedling dry weight (V) of Portulaca oleracea. The same letters show non significant differences 
ment, while the weight of seedlings obtained with $5 \%$ of sage and 5 and $10 \%$ of white wormwood were not significantly affected. On the contrary, the minimum fresh (0.69 $\mathrm{mg})$ and dry $(0.11 \mathrm{mg})$ seedling weight were obtained with $15 \%$ and $20 \%$ of white wormwood and 10,15 and $20 \%$ of sage, with no significant differences among these extract types and concentrations (Fig. 2-IV and Fig. 2-V).

In conclusion, results show that the effect of extract type and concentration strongly interacted and led to different effects according to the different combination of these two experimental factors. Seed germination of purslane was either inhibited or slowed down by the application of little amounts of sage and white wormwood extracts and these effects were greater with sage than with white wormwood. On the contrary, seedling growth of purslane was slightly stimulated by the lowest concentration of sage (5\%), while it was inhibited by higher concentration values. Also in this case, the effect of sage appeared to be stronger than that of white wormwood.

\section{References}

Bagheri, R., M. R. Chaichi, M. Mohseni-Saravi, G. R. Amin and G. Zahedi (2007). Grazing affects essential oil compositions of Artemisia sieberi Besser. Pakistan Journal of Biological Sciences 10(5):810-813.

Culter, H. G. (1988). Biologically active natural products, potential use in agriculture, ACS Symposium Series, p. 380.

D'Antunono, L. F., R. Neri and A. Moretti (2002). Investigations of individual variability of sage (Salvia officinalis) based on morphological and chemical evaluation. Acta Horticulturae (ISHS) 576:181-187.

Duke, S. O. (1987). Weed Physiology. Vol 1.Reproduction and Physiology. Raton, Florida, CRC Press.

Ebana, K., W. Yan, R. H. Dilday, H. Namai and K. Okuno (1981). Variation in the allelopathic effect of rice with water soluble extracts. Agronomy Journal 93:12-16.

Ellis, R. A. and E. H. Roberts (1981). The quantification of ageing and survival in orthodox seeds. Seed Science and Technology 9:373-409.

Ghorbani-Ghouzhdi, H., A. Sahraroo, H. R. Asghari and H. Abbasdokht (2008). Composition of essential oils of Artemisia sieberi and Artemisia khorasanica from Iran. World Applied Sciences Journal 5(3):363-366.

Hitokoto, H., S. Morozumi, T. Wauke, S. Sakai and H. Kurata (1980). Inhibitory effects of spices on growth and toxin production of toxigenic fungi. Applied and Environmental Microbiology 39:818-822.

Holm, L. G., D. L. Plucknett, J. V. Pancho and J. P. Herberger (1977). The World's Worst Weeds. Distribution and Biology. University Press of Hawaii, Honolulu, Hawaii.

Lanciotti, R., A. Gianotti, F. Patrignani, N. Belletti, M. E. Gurezoni and F. Gardini (2004). Use of natural aroma compounds to improve shelf-life and safety of minimally processed fruits. Trends in Food Science \& Technology 15:201-208.

Maguire, J. D. (1962). Speed of germination aid in selection and evaluation for seed vigour. Crop Science 2:176-177.

Mirjalili, M. H., P. Salehi, A. Sonboli and M. Mohammadi Vala (2006). Essential oil variation of Salvia officinalis aerial parts during its phenological cycle. Chemistry of Natural Compounds 42:19-23.

Miyanishi, K. and P. B. Cavers (1980). The biology of Canadian weeds. 40. Portulaca oleracea L. Canadian Journal of Plant Science 60:953-963.

Mozaffarian, V. (1996). A Dictionary of Iranian Plant Names. Farhang Moaser Publishers, Tehran, Iran.

Ramezani, M., J. Behravan and A. Yazdinezhad (2004). Chemical composition and antimicrobial activity of the volatile of Artemisia khorasanica from Iran. Pharmaceutical Biology 42:599-602.

Rice, E. L. (1984). Allelopathy, $2^{\text {nd }}$ ed. Academic Press Inc, London.

Steinsiek, J. W., L. R. Oliver and F. C. Collins (1982). Allelopatic potential of wheat (Triticum aestivum) straw on selected weed species. Weed Science 30:495-497.

Tan, R. X., W. F. Zheng and H. Q. Tang (1998). Biologically active substances from the genus Artemisia. Planta Medica 64(4):295-302.

Vazquez, B. I., C. Fente, C. M. Franco, M. J. Vazquez and A. Cepeda (2001). Inhibitory effects of eugenol and thymol on Penicillium citrinum strains in culture media and cheese. International Journal of Food Microbiology 67:157-163.

Waller, G. R. (2004). Introduction-reality and future of allelopathy. pp.1-12. In: F. A. Macias, J. C. G. Galindo, J. M. G. Molinillo and H. G. Culter (Eds.). Allelopathy, Chemistry and Mode of Action of Allelochemicals. CRC Press, New York, USA.

Waterhouse, D. F. (1993a). The major arthropod pests and weeds of agriculture in Southeast Asia: distribution, importance and origin. ACIAR Monograph No. 21. Australian Center for International Agricultural Research, Canberra, Australia.

Waterhouse, D. F. (1993b). Biological Control: Pacifc Prospects. Supplement 2. Australian Center for International Agricultural Research (ACIAR), Canberra, Australia.

Waterhouse, D. F. (1994). Biological Control of Weeds: Southeast Asian Prospects. ACIAR Monograph No. 26, Australian Center for International Agricultural Research (ACIAR), Australia.

Weyerstahl, P., S. Schneider, H. Marschall and A. Rustaiyan (1993). The essential oil of Artemisia sieberi Bess. Flavour and Fragrance Journal 8:139-145. 